\title{
APLIKASI TEKNIK SEMANTIK UNTUK MENINGKATKAN KUALITAS MASTER OF CEREMONY
}

\author{
Yuli Yulianti ${ }^{1}$,Wawang Adidharma ${ }^{2}$,Rosse Neverterry ${ }^{3}$ \\ AKPAR Citra Buana Indonesia \\ 1yuliyulianti@cbi.ac.id \\ ${ }^{2}$ wawang@cbi.ac.id \\ 3akpar@cbi.ac.id
}

\begin{abstract}
The purpose of this paper is to provide an explanation of the application of semantics to improve the quality of the master of ceremonies. The meaning and implications of the application of semantic applications and those related to semantics. Semantics is related to a science of meaning, symbols contained in language conveyed by a master of ceremonies. Basically, semantic techniques are very important to be mastered by the master of ceremonies, so that in guiding the event it is more conceptualized by assembling vocabulary using good language. and correct with an adequate blend of language, flexible positive thinking able to produce good, polite, able to use time well and not wasting time on things that are not good. With semantic techniques to improve the quality of master of ceremonies, is to understand semantic techniques What are the implications of the semantic technique. Meanwhile, the key to the master of ceremony is high self-confidence, practicing vocals, articulations, comfortable costumes and being able to adapt to the event so that they can be more flexible in interacting with the audience from opening to closing.
\end{abstract}

Keywords: Semantic technique, Application of semantic technique, Implication of semantic technique

Abstrak - Tujuan penulisan ini adalah untuk memberikan penjelasan tentang aplikasi semantik untuk meningkatkan kualitas master of ceremony.Makna dan implikasi penerapan aplikasi semantik serta yang berkaitan tentang semantik. Semantik berhubungan dengan sebuah ilmu tentang makna,simbol-simbol yang terkandung pada Bahasa yang disampaikan oleh seorang master of ceremony.Pada dasarnya Teknik semantik sangat penting untuk dikuasai oleh master of ceremony,agar dalam memandu acara lebih terkonsep dengan merangkai kosa kata memakai Bahasa yang baik dan benar dengan paduan Bahasa yang sudah memadai,luwes berpikir positif mampu untuk menghasilkan yang baik,sopan,mampu memanfaatkan waktu dengan baik tidak membuang waktu untuk hal-hal yang kurang baik.Dengan Teknik semantik untuk meningkatkan kualitas master of ceremony,adalah memahami Teknik semantik,bagaimana implikasi Teknik semantik tersebut.Sedangkan kunci dari master of ceremony adalah percaya diri yang tinggi,berlatih vocal,artikukali,kostum yang nyaman dan mampu menyesuaikan dengan acara agar bisa lebih luwes dalam berinteraksi dengan audien dari pembukaan hingga penutupan.

Kata Kunci : Teknik semantik,Aplikasi teknik semantik,Implikasi Teknik semantik

\section{PENDAHULUAN}

Berdasarkan penelitian dan analisis yang dilakukan maka, aplikasi teknik semantik untuk meningkatkan kualitas Master of Ceremony (MC) pada mahasiswa Citra Buana Indonesia adalah metode eksperimental (praktek) dan diskusi. Berkaitan dengan Teknik semantik yang digunakan yaitu tentang suatu makna yang digunakan dalam memperluas pembendaharaan kata untuk Master of Ceremony (MC).
Untuk menjadi Master of Ceremony (MC) harus terus belajar dan belajar, karena dalam memandu acara tidak hanya mengandalkan percaya diri saja, namun ilmu pengetahuanpun harus di miliki, diantaranya Teknik semantik sebagai dasar memahami makna atau lambang yang digunakan dalam Master of Ceremony. Master of Ceremony (MC) merupakan orang yang paling pertama dalam berlangsungnya suatu acara, untuk itu MC harus berjiwa besar, rendah hati, memahami audien dan memahami acaranya. 
Hal ini memotivasi para mahasiwa untuk terus berlatih. Pesan dalam bentuk non verbal berupa gesture, mimik muka dan vokal.Menggunakan media bahasa berupa komunikasi secara lisan. Mahasiswa memiliki kemampuan mendengar setelah itu para peserta diminta untuk memperagakan supaya mereka lebih menguasai dalam praktek. Tujuan dari para mahasiswa adalah untuk meningkatkan citra diri di bidang mater of ceremony. Selain itu faktor pendukung seperti fasilitas yang memadai, materi ajar serta antusias dari para mahasiswa. Adapun hambatan yang berasal dari internal para mahasiswa seperti perbedaan karakteristik, hambatan semantik dan hambatan olah vokal.

Untuk menjadi Master of Ceremony yang baik,maka komunikasi harus pandai berkomunikasi,Karena dalam memandu acara komunikasi itu merupakan salah satu penyampaian informasi kepada audien. Berdasarkan penjelasanan diatas, setiap orang lebih banyak menggunakan aktivitasnya dengan berkomunikasi. Dan umumnya komunikasi yang dilakukan dalam berbagai aktivitas lebih banyak menggunakan bahasa lisan (verbal). Melalui komunikasi (verbal) secara langsung, feedback akan segera dapat di ketahui dan dimengerti oleh kedua belah pihak. Sedangkan komunikasi non verbal digunakan sebagai pendukung untuk menguatkan arti dari komunikasi verbal. Komunikasi secara nonverbal banyak menggunakan gerakan tubuh sehingga apa yang disampaikannya dapat dipahami oleh lawan bicara. Demikian halnya aktivitas komunikasi ini dapat dilakukan dalam sebuah ruangan ketika melakukan kegiatan Master of Ceremony atau dalam kegiatan lainnya dalam bersosialisasi.

Sedangkan kegiatan komunikasi dalam kelas pengajar kerap membagi dalam kelompok besar dan kecil. Tujuannya adalah untuk memudahkan dalam memberikan evaluasi dari suatu proses pembelajaran. Ketika pembelajaran secara tatap muka komunikasi ini sangat penting agar tercipta suasana yang nyaman menyenangkan dan dapat tercapainya suatu pembelajaran.

Berbicara merupakan sebuah alat untuk menyampaikan sesuatu hal kepada lawan bicara. Sedangkan berbicara didepan umum merupakan suatu keterampilan seseorang.Namun dalam berbicara didepan umum ini tidak semua orang mampu dan terampil,padahal ini merupakan hal yang sangat penting dalam kehidupan sehari-hari baik di dunia kerja ataupun dalam hidup bermasyarakat.

Untuk mengasah keterampilan berbicara di muka umum,bisa mengikuti pelatihan-pelatihan yang berhubungan dengan public speaking.Karena public speaking ini sangat diperlukan khususnya untuk Master of Ceremony.Selain mengikuti pelatihan juga harus sering praktek atau berlatih menjadi Master of Ceremony baik dalam acara formal maupun nonformal. Karena semakin banyak parktek maka akan semakin terlatih baik penguasaan Bahasa maupun penguasaan panggung, bisa terlihat dari jam terbang yang sudah banyak.

Berbicara di depan orang banyak bisa di mulai dengan cara memberikan informasi,memotivasi ataupun bercerita yang tujuannya apa yang di sampaikan tersebut dapat dipahami oleh lawan bicara,seperti Master of Ceremony (MC) ketika memandu acara tentunya harus dipahami oleh audien.Ketika audien memahami apa yang disamapaikan oleh Master of Ceremony maka acara akan berlangsung dengan baik.

Berbicara dimuka umum salah satunya yaitu Master of Ceremony 
(MC).Menjadi Master of Ceremony ini memerlukan ke ahlian,keterampilan.Jadi Master of Ceremony (MC) ini tugasnya memandu suatu acara dari mulai persiapan hingga acara selesai. Master of Ceremony (MC) dalam suatu acara merupakan suatu ujung tombak yang paling utama dalam acara,baik atau tidaknya acara itu tergantung kepada pemandu acara.

Master of Ceremony (MC) merupakan suatu model, yang mana audien akan tertuju pada MC.Oleh karena itu menjadi Master of Ceremony (MC) tidaklah mudah, karena Master of Ceremony (MC) harus percaya diri,menguasai acara, bersikap tenang dan tersenyum,memakai kostum yang tepat (Suara.com,2021)

Master of Ceremony (MC) bisa dijadikan jenjang karier bagi orang yang yang mempunyai motivasi dan mau belajar lebih banyak tentang bagaimana memandu acara baik secara formal maupun non formal,bagi mahasiswa Akpar Citra Buana Indonesia merupakan suatu peluang untuk meningkatkan public speaking karena akademi pariwisata ini berhubungan dengan orang-orang baik wisatawan maupun tamu di hotel.

Oleh karena itu, Akademi Pariwisata Citra Buana Indonesia sebagai salah satu perguruan tinggi yang salah satunya mempunyai yang dengan populasi generasi millennial yang mana mahasiswa selain kemampuan dibidang akademik sebaiknya mahasiswapun memiliki kemampuan tertentu seperti public speaking atau Master of Ceremony (MC).

Apabila mahasiswa mempunyai kemampuan terutama dalam Master of Ceremony,maka akan memperbesar peluang kerja dan potensi diri mahasiswa tersebut setelah lulus dari Akpar Citra Buana Indonesia. Tidak usah takut susah bekerja ketika fokus belajar menjadi Master of Ceremony (MC),tetapi jadikan ini suatu motivasi bahwa suatu saat akan menjadi Master of Ceremony yang profesional dan dibutuhkan oleh orang banyak.

Dalam sebuah acara Master of Ceremony (MC) tugasnya memandu acara tentunya harus mempersiapkan diri dengan matang,selain berlatih vocal gestur tubuh ataupun kostum harus diperhatikan dengan acara.Jika segala sesuatunya dipersiapkan dengan baik maka acara akan berjalan lancar dan hasilnya baik.Kesuksesan acara tergantun pada pemandu acara,jika pemandu acara piawai dalam mengendalikan situasi maka akan tertanam kesan yang baik untuk audien.

Selain percaya diri,keterampilan berbicara, piawai merangkai kata, luwes, memilih kalimat yang tepat juga perlu dikuasai oleh Master of Ceremony (MC).Jika sudah bisa menguasai makan akan mudah ketika memandu acara.Teknik semantic ini kenapa sangat penting untuk Master of Ceremony, karena banyak makna yang berkaitan dengan Bahasa, terutama saat memandu acara.

Dari paparan diatas berdasarkan hakikat kedudukan dan fungsi Master of Ceremony maka dapat ditarik urgensi masalah yang fokus untuk dijawab yang mengadung implikasi. Masalah yang akan dicari penyelesainya pada penelitian ini adalah tentang bagaimana meningkatkan kualitas Master of Ceremony dengan mengaplikasikan teknik semantik beserta implikasinya.

\section{METODE PENELITIAN}

Dalam penelitian ini, akan membahas masalah secara mendalam, mengaitkan antar berbagai fenomena, menginterpretasikan serta mampu memahami dan menjawab masalah yang sesungguhnya pada tataran kualitatif, yang lebih ke pada makna dan implikasi 
tanpa menyimpulkan secara generalisasi.

Aplikasi Deskriptif Kualitatatif meliputi bahwa Teknik semantik Master of Ceremony (MC) yang mana harus menguasai hard skill dan soft skill. Selain itu harus mempunyai keterampilan dasar sikap dan kepribadian yang baik untuk menjadi Master of Ceremony (MC), ini berkaitan dengan hard skill. Sedangkan berkaitan dengan soft skillnya harus pandai berkomunikasi dengan baik agar mampu menjadi Master of Ceremony dalam berbagai acara.

Teknik semantik ini yang berkaitan dengan makna dalam Bahasa sehingga dalam Master of Ceremony ini sangat baik untuk dikuasai sebagai dasar menuju Master of Ceremony yang professional. Sehingga dalam metode penelitian ini digunakan observasi dengan melihat Master of Ceremony yang professional.

\section{A. Teknik Pengumpulan data dan Pengambilan Data}

Berdasarkan referensi dari berbagai sumber, artikel, buku, prosiding dan internet. Referensi dari internet merupakan data atau sumber yang sudah diteliti atau di uji oleh para ahli dan beberapa pakar.

Berdasarkan observasi secara online melihat dari beberapa Master of Ceremony dalam bertugas memadu acara Master of Ceremony ternama dengan sample master of ceremony atau presenter yaitu Ivy Batuta, Melissa Karim dan Rendy Wicaksana.Yang mana mereka masing-masing dari mereka memiliki pengalaman dan latar belakang sebagai penyiar radio, MC dan presenter.

Dari beberapa sample tersebut di ambil data dengan observasi online saat masing-masing menjadi master of ceremony dan membaca profile Ivy
Batuta. Dari mulai perjalanan kariernya hingga sukses menjadi presenter televisi atau master of ceremony.

\section{HASIL DAN PEMBAHASAHAN PENELITIAN}

\section{Aplikasi Teknik Semantik terhadap Master of Ceremony}

Semantik merupakan suatu pembelajaran tentang makna yang biasanya dikaitkan dengan simbolsimbol sederhana.Selain itu ada juga yang mengartikan bahwa semantik sebagai pembelajaran tentang arti untuk memahami ekpresi manusia melalui Bahasa.

Menurut pendapat para ahli ada yang mengemukakan bahwa semantik merupakan hubungan makna dengan konsep atau makna dari kata tersebut,atau berkaitan dengan suatu benda yang mengarah kepada makna yang berada diluar Bahasa. Jadi kata semantik secara garis besar pembelajaran suatu makna melalui Bahasa.

Makna semantik yang berkaitan dengan Master of Ceremony ini bagaimana bisa mengendalikan situasi supaya audien fokus terhadap MC dan paham apa yang di sampaikan oleh MC sehingga acaranya berjalan dengan baik. Dari penggunaan kata, tanda baca, intonasi, gestural sehingga mampu membawa suasana acara menjadi lebih meriah.

Menjadi Master of Ceremony (MC) harus ditunjang dari berbagai aspek bukan hanya bermodalkan suara yang bagus saja namun mulai dari ilmu pengetahuan, keterampilan, hingga ferfomance harus diperhatikan. Master of Ceremony (MC) harus mampu menarik perhatian orang banyak atau audien, menghibur untuk membangkitkan semangat audien.

Ada beberapa jenis semantik diantaranya, semantik konseptual yang merupakan makna konotatif dan makna 
kognitif yang merupakan faktor sentral dalam komunikasi berbahasa serta tersusun dengan komplek. selain itu ada juga semantik denotatif, makna ini merupakan makna yang sebenarnya atau makna asli.Dari jenis semantik tersebut jika dipadukan dalam memandu acara akan terdengar lebih indah dan terlihat pemandu acara lebih professional yang ditunjang dengan ilmu pengetahuan.

Dalam semantik ini ada yang disebut makna luas artinya makna yang terkandung dalam suatu kata lebih luas dari apa yang diperkirakan.Sedangkan makna sempit merupakan kebalikan dari makna luas yaitu makna lebih sempit dari uraiannya. Dalam Master of Ceremony (MC) perlu juga makna kiasan. Jadi dengan berbagai Bahasa dengan makna yang digunakan dalam Master of Ceremony (MC) acara yang dipandu akan dikuasai dan berjalan dengan baik.

Untuk meningkatkan kualitas Master of Ceremony diantaranya kepercayaan diri, kemampuan manajemen, pandai beradaptasi dan beretika yang baik.Maka seorang master of ceremony harus meningkatkan ilmu pengetahuan mulai dari berbahasa,berbusana,make up dan cara berinteraksi dengan audien.Karena master of ceremony merupakan pusat perhatian utama audien baik buruknya dapat lebih mudah di nilai oleh audien.

Salah satu Master of Ceremony Indonesia terbaik Ivy Batuta sebagai seorang Master of Ceremony baik di televisi ataupun radio, berkata menjadi MC modalnya tidak hanya cuap-cuap saja, tapi ia harus paham beragam hal. Mulai dari teknik vokal hingga penampilan saat bertugas. Meskipun belajar menjadi MC secara otodidak, tetapi patut menambah ilmu dengan berguru pada pakarnya. Untuk meningkatkan skill di dunia MC. Yang sudah berpengalaman selama 15 tahun di dunia public speaking ini, saat ini MC dituntut untuk bisa menguasai bahasa Inggris dalam acara-acara resmi yang digelar perusahaan-perusahaan tertentu.

Namun, ternyata banyak perusahaan yang masih belum yakin kemampuan MC Indonesia membawakan acara dalam bahasa Inggris. Teknik aplikasi semantik yang sangat penting karena semantik ini tentang makna dalam meningkatkan kualitas Master of Ceremony maka dalam berbicara Ivy Batuta ini tidak hanya asal cuap-cuap saja tapi harus dikuasai tekniknya. Untuk meningkatkan kualitas sebagai Master of Ceremony,diantarantanya harus menguasai beberapa Teknik berbicara seperti yang tercantum dibawah ini:

a) Phrasing. Seorang $M C$ harus menguasai pembagian atau pemenggalan kata dalam sebuah kalimat.Dengan adanya pembagian kata untuk memudahkan penonton menerima pesan secara jelas.

b) Articulation. Kejelasan pengucapan huruf, suku kata atau pun kata, akan menambahkan skill dalam berbicara di depan umum. Tujuannya, agar audiens bisa mengerti apa yang disampaikan oleh $M C$. Dengan begini, audiens akan menikmati berjalannya seluruh acara jika $M C$ berbicara dengan artikulasi yang jelas.

c) Speed. Kecepatan pengucapan yang wajib diketahui seorang MC dalam mengucapkan kata yang diperkirakan 110 sampai 130 kata per menitnya. Beberapa hal yang harus diperhatikan dalam mengucapkan kata diantaranya, jika terlalu lambat, acara akan menjadi monoton. Sedangkan, apabila terlalu cepat, audiens akan tidak tertarik, tidak peduli, bahkan tidak 
memahami apa yang disampaikan oleh pemandu acara tersebut. Maka, $M C$ harus selalu menjaga tingkat kecepatannya saat berbicara.

d) Stressing. Sebelum acara dimulai seorang $M C$ akan hadir lebih awal untuk mempelajari isi dari keseluruhan acara. Dengan memberi tekanan pada kata-kata yang dimaksud. Hal ini dilakukan untuk menetukan kalimat mana yang harus diberi penekanan.

e) Intonation. Tinggi rendahnya, irama, lagu dan kalimat, digunakan $M C$ untuk menarik pendengar agar memperhatikannya. Tujuannya adalah untuk menghindari acara yang monoton, dan kejenuhan audiens. Jika terjadi kebosanan pada audiens, gunakanlah intonasi yang sedikit tinngi untuk mengembalikan fokus peserta kepada $M C$.

f) Pause. Seorang $M C$ harus pandai dalam mengambil kesempatan untuk mengatur pernafasannya. Dengan begitu, hal tersebut akan memudahkan $M C$ dalam berbicara menggunakan artikulasi yang jelas. Pendengar pun akan mengerti isi dari seluruh acara tersebut. Untuk melirikcue card juga dapat dilakukan seorang $M C$ saat berhenti sejenak mengambil nafas.

Dalam suatu acara Master of ceremony juga di kenal dengan $\mathrm{MC}$ atau pemandu acara,yang mana memandu jalannya acara dari awal hingga selesai,acara yang di pandu biasanya acara resmi (formal),non formal ( tidak resmi),pesta dan lain-lain. Dalam hal ini biasanya pembawa acara biasanya menyampaikaninformasi,menyampaika n susunan acara,pemateri,pengumuman dan berinteraksi dengan audien agar acara berjalan baik samapai acara selesai.
Meskipun menjadi pembawa acara mungkin tampak seperti tugas yang menakutkan, ada beberapa cara yang dapat memakukan tanggung jawab sebagai MC, memancarkan kepercayaan diri dan karisma untuk menjaga upacara tetap menghibur bagi semua orang.Disini seseorang betul-betul harus bisa menguasai dirinya agar mampu dan bisa memandu acara yang sudah ditugaskan,bahkan punya keyakinan bahwa dirinya bisa dengan memantapkan persiapan dan memahami acara yang akan dipandunya.

Mengingat pentingnya suatu acara yang akan dipandu baik acara pernikahan,wisuda,ulang tahun,work shop,seminar dan lain-lain.Maka seorang master of ceremony atau MC harus bisa menyesuaikan dan bisa menguasai acara sehingga acara bisa berjalan dengan baik,sesuai dengan tema yang sudah ditentukan oleh panitia atau struktur yang terkait.

Untuk mengetahui acara dan susunan acara yang akan dipandu oleh master of ceremony (MC),sebaiknya master of ceremony menemui struktur atau kepanitian yang mengadakan acara agar jadwal kegiatan dapat di tinjau dan direncanakan terlebih dahulu secara matang agar nantinya acara sesuai dengan harapan penyelenggara.

Master of ceremony bertugs sebagai pemegang tanggung jawab berlangsungnya acara dari awal sampai akhir.Selain itu master of ceremony harus mampu menciptakan suasana yang bervariasi seperti menyenangkan,energik supaya audien tidak ngantuk,sehingga audien bisa fokus memperhatikan pemateri.Ketika audien fokus dan senang menerima materi maka pemateripun serasa di hargai.Walaupun kadang ada audien tidak mau mendengarkan materi karena ngantuk, disini peran pemandu acara 
supaya audien terlibat dan senang menerima materi.

Jadi master of ceremony atau (MC) harus bisa memahami dan sigap pada situasi apapun yang dihadapi ketika acara berlangsung,ekspektasi sebagaimana tugas Master of Ceremony, lakukan sesuai riset, tetap teratur hingga acara berakhir.Dengan ini aplikasi semantik sangat berkaitan dengan master of ceremony karena makna dan gaya Bahasa yang digunakan.

Melihat perjalanan karier Ivy Batuta yang berdarah Minangkabau,beliau awal memulai kariernya pada intertaiment beliau di jadikan penyiar radio indika yang terletak di wilayah Jakarta.Dengan berjalannya waktu Ivy Batuta terus mengasah ilmunya hingga beliau mencoba terjun ke dunia seni peran dan presenter. Dengan berpengalaman menjadi penyiar radio Ivy Batuta berani mencoba ke mampuannya sebagai seorang presenter televisi dengan percaya yang tinggi,sehingga beliau bisa melakukannya pada acara ofline ataupun online.Dengan modal percaya dirinya beliau bisa sukses pada karier master of ceremony.

Eksistensi Master of Ceremony (MC) memang tak perlu diragukan lagi. Hampir semua acara pasti membutuhkan kehadiran MC. Hal itu menginspirasi presenter kondang Ivy Batuta untuk menghimpun para MC ke dalam satu wadah khusus Master of Ceremony Management (McM).

Tak sendirian, Ivy turut mengajak serta 12 rekan MC lain seperti Melissa Karim, Vivit Kavi, dan Rahma Umayya. Tak hanya mengelola jadwal para MC, kehadiran McM juga diharapkan bisa mengembangkan kemampuan para pembawa acara.

"Ada suatu kecenderungan, MC butuh yang bisa bilingual (dua bahasa). Dan di sini para talent kita akan sama-sama belajar, yang penting punya keinginan belajar. Jadi tidak hanya bekerja tapi juga bisa mengembangkan kemampuan, Aplikasi Teknik semantik terhadap Master of Ceremony "Selain itu bukan hanya lancar berbicara, tapi para talent juga dipastikan untuk bisa menghandle situasi. Sehingga tidak akan panik jika ada situasi buruk yang terjadi,"

Berbagai ilmu pengetahuan dan pengalaman dengan banyaknya jam terbang menjadi seorang presenter namun tidak membuat Ivy Batuta sombong,beliau tetap mencoba membagi ilmunya kepada orang yang membutuhkan ilmu komunikasi dengan cara menjadi seorang guru dalam pelatihan yang berkaitan dengan komunikasi khususnya dibidang master of ceremony atau presenter,selain itu Ivy Batutapun mengajak rekanrekannya untuk bergabung membuat Talent Agency Management yang diberi nama McM (Master of Ceremony Management) yang memfokuskan ke ahlian Master of Ceremony,yang bertujuan Master of Ceremony ini mampu menguasai teknik-teknik berbicara Phrasing, Articulation, Speed, Stressing, Intonation, Pause sebagai peningkatan kualitas master of ceremony yang professional.

\section{Kelebihan Aplikasi Teknik semantik Terhadap Master of Ceremony}

Penerapan aplikasi teknik semantik ini memberikan dampak positif bagi mahasiswa dalam memandu acara dalam berbagai kegiatan. Dengan mengaplikasikan Teknik semantik mampu meningkatkan kualitas mahasiswa berwawasan luas dalam memandu acara,diantaranya mampu merangkai kata dengan bermacammacam kosa kata,sehingga terlihat luwes,bisa menyesuaikan 
diri,berkepribadian yang baik pada dirinya maupun orang lain,berbahasa yang santun,tenang dalam situasi apapun dan mampu disiplin dengan memanfaatkan waktu sebaik mungkin.

Kelebihan dari aplikasi semantik terhadap master of ceremony,bisa terlihat ketika MC memandu acara dengan menggunakan Bahasa yang mengandung berbagai makna dan mampu memadukan simbol-simbol yang tercantum pada acara seperti dalam menyebutkan nama,gelar jabatan.Master of ceremony (MC) tetap semangat memberikan sikap terbaik mengatur artikulasi,intonasi sesuai acara yang dipandunya baik resmi ataupun tidak resmi.

Menjadi master of ceremony tidak semua mampu dan trampil. Namun paling utama percaya diri dan mau belajar dan belajar. Bagi seseorang yang tidak biasa memandu acara maka akan terlihat gugup berhadapan dengan audien yang biasa dikatakan demam panggung.Oleh karena itu untuk menghindari hal tersebut ada beberapa trik yang harus dipersiapkan agar tidak gugup diantaranya persiapkan materi dan kuasai materi,tarik napas yang panjang,hindari makanan yang membuat tidak nyaman tenggorokan,perbanyak minum air putih,selalu tersenyum dan pakailah kostum yang membuat nyaman.

Aplikasi semantik untuk master of ceremony (MC) dapat diterapkan sebagai rencana untuk membuat sebuah ide atau gagasan,yang mana gagasan tersebut akan dikembangkan secara luas ketika memandu acara, ketika memandu acara tentunya master of ceremony merangkai kata dengan berbicara menggunakan Bahasa yang baik dan benar.

\section{Makna dan Implikasi Penerapan Teknik Semantik Terhadap Master of Ceremony}

Berbicara di depan umum itu ada berbagai macam,salah satunya seperti pidato,ceramah,menjadi seorang master of ceremony (MC) dan banyak kegiatan lain yang berhubungan dengan kegiatan yang berbicara didepan umum atau orang banyak.Ketika di kasih tugas untuk komunikasi di depan orang atau audien,kebanyakan orang menghindar karena merasa tidak bisa tidak mampu.

Tugas berbicara di depan orang banyak atau audien memang bukan hal yang mudah tentunya harus banyak berlatih agar bisa menguasai panggung bukan demam panggung. Namun ketika mengalami demam panggung jangan di anggap hal yang negatif namun buatlah sebauh motivasi agar lebih mempersiapkan diri untuk menguasai materi,mental dan penampilan untuk lebih baik lagi.Maka dari itu cari darimana penyebabnya dan bagaimana solusinya agar terhindar dari hal-hal yang menghambat tampil di depan audien.

Kunci menjadi master of ceremony (MC) adalah percaya diri yang tinggi bahwa diri kita mampu memimpin jalannya acara dengan baik.Master of ceremony (MC) ini kegiatan berbicara di depan audien maknanya bukan hanya sekedar berbicara namun bisa meningkatkan eksistensi seseorang menjadi lebih dikenal,apalagi berbicaranya yang mempunyai nilai informasi,memotivasi,menghibur dan menarik sehingga audien terpengaruh untuk lebih memperhatikan atau fokus pada acara.

Hakikatnya semua manusia mampu berbicara,karena bersosialisasi dalam kehidupan sehari-hari tentunya dengan cara berbicara atau komunikasi.Setiap manusia mempunyai seni berbicara atau 
retorika berbicara,yang mana seseorang dapat berkomunikasi lisan dengan tatap muka kepada sejumlah orang.Kegiatan komunikasi ini sering dilakukan bukan hanya memandu acara namun dalam berinteraksi di masyarakatpun dengan cara berkomunikasi.

Implikasi penerapan aplikasi semantik pada master of ceremony (MC) mampu memberikan Bahasa yang baik dan benar ketika memandu acara.Dalam setiap acara pemandu acara harus selalu ada sebagai pengatur jalannya acara.sukses dan tidaknya sebuah acara tergantung pada master of ceremony (MC).Jika seorang pemandu acara mampu mensukseskan acara tersebut,maka akan membawa kesan yang baik buat audien ataupun siapa saja yang hadir dan mendengar pada acara tersebut.

Dalam mengaplikasikan Teknik semantik Master ,karena of Ceremony paling pertama percaya diri dengan percaya diri sudah pasti mampu mneguasai jalannya acara dengan mudah.Pembawa acara jangan hanya menerima tawaran atau bayarannya saja namun profesionalisme dalam memandu acara harus tetap diperhatikan agar memberikan kepercayaan kepada orang yang mengadakan acara.

Kepuasan penyelenggara dalam suksesnya acara maka akan terlihat profesionalnya pemandu acara,maka dari itu pemandu acara harus komunikatif dengan penyelenggara acara bukan hanya pada hari dimana acara berlangsung,namun ketika ada pertemuan sebelum hari pelaksanaan acara sebaiknya pemandu acara ikut hadir agar dalam pembuatan riset ataupun topik yang akan di pandunya bisa sesuai dengan harapan yang penyelenggara,selain itu pemandu acarapun akan lebih mudah mengatur jalannya acara dari mulai pembukaan hingga penutupan.

\section{KESIMPULAN}

Teknik semantik sebagai salah satu teknik yang digunakan untuk peningkatan kualitas Master of Ceremony (MC). Penerapan aplikasi teknik semantik ini memberikan dampak positif bagi mahasiswa dalam memandu acara dalam berbagai kegiatan. Kelebihan Aplikasi Teknik semantik, dengan mengaplikasikan teknik semantik mampu meningkatkan kualitas mahasiswa berwawasan luas dalam memandu acara, diantaranya dalam merangkai beberapa kosa kata dengan berbagai kata,berbicara yang baik dan benar,bersikap yang baik terhadap diri sendiri dan orang lain,luwes,mampu bersosialisasi dengan orang lain baik pada acara formal ataupun non formal,terlihat tenang dan sigap dalam menyikapi hal-hal yang terjadi pada acara yang dipandunya sehingga acara tetap berjalan dengan baik sampai akhir.

Karena semantik ini,sangat penting bagi master of ceremony karena berkaitan dengan sosial yang berhubungan dengan komunikasi, jadi semantik ini sangat baik untuk Master of Ceremony (MC), dengan teknik semantik ini mampu menguasai beberapa teknik berbicara saat berkomunikasi langsung dengan audien. Sedangkan makna dan Implikasi Penerapan Teknik Semantik Terhadap Master of Ceremony yaitu salah satu cara meningkatkan eksistensi semantik dihadapan orang lain yang tujuannya bukan hanya sekedar berbicara namun harus berbicara yang lebih baik lagi yang mempunyai retorika,artinya mempunyai seni dalam berkomunikasi lisan secara tatap muka kepada sejumlah orang.

Aplikasi Teknik semantik sangat baik untuk dipadukan pada master of ceremony,karena banyak makna,smbol yang berkaitan dengan acara bisa lebih 
mudah untuk merangkai Bahasa dari mulai Bahasa baku,kiasan,energik,humoris bahkan bisa mampu improvisasi gaya
Bahasa.Tujuan aplikasi semantik meningkatkan master of ceremony ini menambah wawasan perpaduan Bahasa yang lebih baik dalam memandu acara.

\section{DAFTAR PUSTAKA}

Aikhenvald, Alexandra (2001). "Introduction". Dalam Alexandra Y. Aikhenvald; R. M. W. Dixon. Areal diffusion and genetic inheritance: problems in comparative linguistics. Oxford: Oxford University Press. hlm. 1-26.

Cruse, Alan; Meaning and Language: An introduction to Semantics and Pragmatics, Chapter 1, Oxford Textbooks in Linguistics, 2004; Kearns, Kate; Semantics, Palgrave MacMillan 2000; Cruse, D. A.; Lexical Semantics, Cambridge, MA, 1986.

Elly Juniarty dan Pramana, (2006), General Public Speaking: seputar publik speaking, Jakarta: public speaking school.I

Experience, U., Interaction, H. R., Inquiry, C., Scale, R., Space, S., Checklists, I. C., \& Questionnaires, Q. (2019). Before You Choose an Activity Empirical UX Evaluation: Data Collec- tion Methods and Techniques UX Evaluation Introduction Semantic Similarity , Cognitive Psychol- ogy of International usability testing Self-Reported Metrics Attitude Change : Psychological Mass Communication: Empirical Re- search Designing Interaction Strategies for Companions Interacting with Children.

Hafizah, E. (2019). IMPLEMENTASI TATA LAKSANA PEDOMAN MASTER OF CEREMONY (MC) BAGI SISWA-SISWI SEKOLAH DASAR (Studi Kasus pada Siswa-Siswi Sekolah Dasar Alam Mahira Kota Bengkulu). Al-Hikmah, 13(1), 77. https://doi.org/10.24260/al-hikmah.v13i1.1336.

Januharso, R Trijono, (2003), Pedoman Keprotokolan dan Master of Ceremony, Semarang, Dahara Price.

Khairiyah Sartika, (2014), 12 MC dan Presenter Bergabung Dalam Master of Ceremony

Management,https://www.tabloidbintang.com/berita/sosok/read/13066/12-mcdan-presenter-bergabung-dalam-master-of-ceremony-management

Kharina Triananda, (2014), "Talent Management Agency", Jakarta. https://www.beritasatu.com/hiburan/214188/bersama-rekannya-ivy-batutaluncurkan-talent-management-agency.

Mario Alinei, (1987). Aspect OF Language. Amsterdam.

Marta Kagan, (2007), 11 Public Speaking Tips From the World's Best Speakers \& Communication Experts, https://blog.hubspot.com/blog/tabid/6307/bid/34274/7-lessons-from-the-worlds-most-captivating-presenters-slideshare.aspx.

Nafinuddin, S. (2020). Pengantar semantik (pengertian, hakikat, jenis). Pengantar Sematik, 1-21. https://doi.org/10.31219/osf.io/b8ws3.

Ninla Elmawati Falabiba. (2019). No Title No Title No Title. 26-35.

Nofrion. (2019). No Title No Title. Teknik Menjadi Pembawa Acara, 53(9), 16891699.

Noermanzah, N., Syafryadin, S., Castrena, O. W., \& Abid, S. (2020). Rhetoric Structure of the Master of Ceremony and the Function of the Akikah Event in Lubuklinggau City. Journal of English Education and Teaching, 4(2), 232-247. 
https://doi.org/10.33369/jeet.4.2.232-247.

Rachel Wolff August 13th, (2020) https://monkeylearn.com/blog/semantic-analysis/

Poerwandari, E.K, (2001), Penelitian Kualitatif dalam Penelitian Psikologi, Jakarta, LPSP3.

Rivan Aditya, (2021), 4 TIPS JADI MC atau PEMBAWA ACARA YANG BAIK UNTUK PEMULA.https://amp.suara.com/lifestyle/2021/02/02/104756/4-tipsjadi-mc-atau-pembawa-acara-yang-baik-untuk-pemula.

Rumpoko, Hadi, (2013), Panduan pidato dan MC yang memukau, Smart Pustaka, Yogyakarta.

Siti Anissa, (2019), 6 Teknik Pengolahan Kata yang Wajib Dikuasi oleh Master of Ceremony (MC). https://diamma.com/2019/03/10/6-teknik-pengolahan-katayang-wajib-dikuasi-oleh-master-of-ceremony-mc/amp/

Structures, M. B. (n.d.). No Covariance structure analysis of health-related indicators in the elderly at home with a focus on subjective health. 6(April 2020), 13-24.

Umurova, X. (2020). SEMANTIC PROPERTIES OF THE TERMS OF WEDDING CEREMONY USED IN BUKHARA DIALECT A Senior Teacher of English Linguistics Department. 6(9), 58-62.

Universitas prof. dr. moestopo (beragama) fakultas ilmu komunikasi.

Wiyanto, Asul dan Astuti, Prima K, (2002), Terampil Membawa Acara, Jakarta, Grasindo.

Yulianita, Neni. (2003). "Pengantar, Ruang Lingkup, Tugas dan Fungsi Protokoler". Makalah pada Pelatihan Protokoler dan MC UKM PROTOKOLER, Universitas Islam Bandung.

Yuningsih, Ani. (2003). "Panduan Praktis Menyusun Acara dan Menjadi Pemandu Acara (MC)". Makalah pada Pelatihan Protokoler dan MC UKM PROTOKOLER, Universitas Islam Bandung. 